\title{
Characteristics of Misinformation Spreading on Social Media During the COVID-19 Outbreak in China: A Descriptive Analysis
}

\author{
Kelin Chen $\mathbb{D}^{\prime}$ \\ Yuni Luo (iD) ${ }^{\prime}$ \\ Anyang $\mathrm{Hu}\left(\mathbb{D}^{2}\right.$ \\ Ji Zhao ${ }^{3}$ \\ Liwei Zhang ${ }^{4}$
}

'Institute of Urban Governance, Shenzhen University, Shenzhen, 518060 , People's Republic of China; ${ }^{2}$ School of Government, University of Chinese Academy of Social Science, Beijing, 102488, People's Republic of China; ${ }^{3}$ School of International and Public Affairs, Shanghai Jiao Tong University, Shanghai, 200030, People's Republic of China; ${ }^{4}$ School of Public Administration, Jilin University, Changchun, I300/2, People's Republic of China
Correspondence: Liwei Zhang

School of Public Administration, Jilin

University, 2699 Qianjin Street,

Changchun, 130012, People's Republic of China

Email zhanglw@jlu.edu.cn
Background: During a public health emergency, social media is a major conduit or vector for spreading health misinformation. Understanding the characteristics of health misinformation can be a premise for rebuking and purposefully correcting such misinformation on social media.

Methods: Using samples of China's misinformation on social media related to the COVID19 outbreak $(\mathrm{N}=547)$, the objective of this article was to illustrate the characteristics of said misinformation on social media in China by descriptive analysis, including the typology, the most-mentioned information, and a developmental timeline.

Results: The results reveal that misinformation related to preventive and therapeutic methods is the most-mentioned type. Other types of misinformation associated with people's daily lives are also widespread. Moreover, cultural and social beliefs have an impact on the perception and propaganda of misinformation, and changes in the crisis situation are relevant to the type variance of misinformation.

Conclusion: Following research results, strategies of health communication for managing misinformation on social media are given, such as credible sources and expert sources. Also, traditional beliefs or perceptions play the vital role in health communication. To sum up, combating misinformation on social media is likely not a single effort to correct misinformation or to prevent its spread. Instead, scholars, journalists, educators, and citizens must collaboratively identify and correct any misinformation.

Keywords: health misinformation, social media, public health emergency, health communication, COVID-19, China

\section{Introduction}

Social media technologies are becoming a reliable platform for health communication to target audiences in a timely manner, which also establishes a hotbed of production, growth, and dissemination of misinformation. ${ }^{1,2}$ For instance, health misinformation emerges in WeChat, a common social networking app in China, such as "chives can kill $99 \%$ of cancer cells" and "rice is the king of junk food". 3 Emergency or risk always plays the role of an opening sluice for misinformation flow. ${ }^{4,5}$ Substantial existing literature has studied the production, classification, vector, process, and propaganda of misinformation in public health emergency, covering the SARS outbreak, the H1N1 influenza, and the Ebola outbreak. ${ }^{6,7}$

In December 2019, the outbreak of COVID-19 was first identified in Wuhan, China, and the World Health Organization (WHO) declared the outbreak a Public 
Health Emergency of International Concern and a pandemic in succession. ${ }^{8,9}$ Similar to previous epidemics, the COVID-19 outbreak has also led to the spread of disease misinformation that the WHO has called "infodemic," and scholars have even asserted that COVID-19 is "the first true social media infodemic". ${ }^{10,11}$ Although the WHO has launched a new information platform called the WHO Information Network for Epidemics, misinformation on social media "goes faster and further like the viruses that travel with people and go faster and further". 5 In view of its severe negative impact on people, combating the infodemic is also a priority during a public health emergency, in parallel with combating the disease. The spread of information can be fundamental in the degree of crisis escalation and its potential impact. In a misinformation context, incomplete understanding and insufficient communication of emotionally charged crisis events may result in confusion and may complicate the solving of a crisis. ${ }^{12}$

Prior to designing and implementing strategies to fight misinformation related to COVID-19, it is necessary to understand the characteristics of misinformation on social media, which would enable us to conduct targeted measurements to eliminate the adverse impact of misinformation, as well as to enhance our cognition on the issue of misinformation in the domains of public health and risk management. Moreover, China, with the occurrence of COVID-19, has basically controlled the outbreak, meaning that the evolution process of misinformation is intact, allowing to more properly analyze the characteristics of misinformation during a public health emergency.

To sum up, the objective of this article is to illustrate the characteristics of misinformation related to COVID-19 on social media in China, including the typology, the most-mentioned misinformation, and the developmental timeline. In the unique context of China, this article also reflects the special Chinese medical beliefs and folk health practices in daily life behind said misinformation. Also, health communication for correcting misinformation and offering genuine health information are given.

\section{Literature Review}

\section{Clarifying Misinformation: An Inclusive Concept}

Although we can easily understand the general concept of misinformation, in academic discussion, clarifying the definition of misinformation is complex. Misinformation has many similar concepts or sub-concepts, such as disinformation, rumors, and fake news. Several official reports or documents regarding misinformation and other concepts are parallel or interchangeable, without distinction or clarification $^{13-15}$ In academic literature, scholars define health misinformation as "a health-related claim of fact that is currently false due to a lack of scientific evidence". ${ }^{16}$ Analogous definitions are used in the distinction between misinformation and disinformation. Scholars define science and health misinformation as information that is contrary to the epistemic consensus of the scientific community regarding a phenomenon. ${ }^{17}$ By this definition, what is considered true and false is constantly changing as new evidence emerges and as techniques and methods are advanced. With respect to disinformation, it is a coordinated or deliberate effort to knowingly circulate misinformation in order to gain money, power, or reputation. ${ }^{17}$ Briefly, misinformation is unintentionally false information, whereas disinformation is intentionally false or inaccurate information that is spread deliberately to deceive and mislead. ${ }^{18}$

The abovementioned distinction conveys that "intentionality" is the core factor to differentiate between misinformation and disinformation. However, variances of the definition remain amongst different researchers and disciplines. ${ }^{19}$ For instance, some scholars attribute fake news and conspiracy theories to the range of misinformation. Under many situations, fake news and conspiracy theories are always based on intention, because they either misinform people or merely attract clicks for the purpose of converting them into advertising money. ${ }^{20-22}$ In the real world, it is difficult to clearly judge a piece of information by an absolute objective or specific standard. During the COVID-19 outbreak in China, a widely spread message was that Shuanghuanglian, a type of traditional Chinese medicine (TCM), can remedy COVID-19. This message resulted in a large-scale panic purchase, and the message was afterward announced as false. According to the explanation of the message source, the original content of the message was confirmed factual. In the dissemination process, this message was leveled and sharpened by social media and the public, which jointly formed its falsity. ${ }^{23}$ In this case, it is difficult to judge whether this message was shared accidentally or deliberately. Perhaps social media users shared this message with the intention of earning the public's attention, clicks, or followers. Likewise, social media users may have believed that this message was factual and that sharing it could help people to choose an 
effective way of preventing the virus. Swire-Thompson and Lazer admit that teasing apart disinformation from misinformation can be extremely difficult, given that the intent behind a message is not always transparent or constant from messenger to messenger. ${ }^{17}$

In addition, the current circumstance shows that not only does the rate of false medical information dissemination explode during a pandemic, but so does miscellaneous messages such as conspiracy theories and death toll reports. ${ }^{24}$ Such messages are amplified by social media and become viral. Exposed to the intricate media-user network and information mess, it is quite difficult to verify misinformation and disinformation as an information receiver.

Therefore, for this paper, we eschew the use of the terms "misinformation" and "disinformation," and based on their common characteristics of being fake and misleading, we regard misinformation as an inclusive concept, where misinformation is a concept set and disinformation is a subset of misinformation. ${ }^{25-27}$ In addition, following Swire-Thompson and Lazer's definition, we include information without hard evidence from the scientific community in the set of misinformation as well. ${ }^{17}$

\section{Factors That Impact the Spreading of Health Misinformation}

Misinformation always spreads in a "florid" environment filled by functional illiteracy, information overload, and confirmation bias. ${ }^{28}$ Especially in a pandemic, misinformation will spread more rapidly and widely, because the public response is very sensitive to epidemics and significant social events, and the public invariably mines diverse types of information regarding potential subsequent risks, which shapes the opportunity for the spreading of misinformation. ${ }^{1}$ Many related works have indicated diverse factors that may influence the spreading of health misinformation.

As Rosnowput forward, there are four factors that can stimulate the misinformation's "journey". ${ }^{29}$ They are general uncertainty, outcome-relevant involvement, personal anxiety, and credulity. Misinformation depends on uncertainty. When the public transfer a misinformation, they must exist in an uncertain information environment. Besides, the misinformation which people believe in is basically associated with people's life or important to the public. During a pandemic, personal anxiety may amplify the transmission of misinformation. ${ }^{30}$ Scholars define anxiety as a negative affective state that is produced by apprehension about an impending, potentially negative, outcome. And scholars also investigated the relationship between the anxiety and personal belief. ${ }^{28,31}$ Briefly, the level of anxiety is notably related to the belief of misinformation.

Credulity is regarded as another factor that has been implicated as a predictor of misinformation spreading. ${ }^{31,32}$ In the public health domain, two factors can impact people's credulity. The one is the health literacy. Health literacy is defined as the degree to which individuals and groups can obtain, process, understand, evaluate, and act upon information needed to make public health decisions that benefit the community. ${ }^{33}$ As usual, public health issues always be complex to the public. The public with low health literacy not only trust a piece of misinformation readily, but also misunderstand an accurate information and turn the information into a piece of misinformation. ${ }^{23}$ Besides, previous research indicated that cultural and social factors profoundly influence health-related behavior as well. ${ }^{23}$ For instance, Chinese people have a stubborn belief about TCM. TCM-related misinformation may mislead the Chinese people easily.

As we mentioned above, the rapid advance of the social media technologies facilitated health communication all over the world, allowing health information to spread rapidly and intensively. ${ }^{28}$ Likewise, social media is a platform of health-related misinformation sharing, such as misinformation surrounding Ebola. ${ }^{34}$ Several characteristics of social media exacerbate the spread of misinformation. Social media make it easy to disseminate information, including misinformation. The public can forward messages to many receivers quite effortlessly; it is often as simple as a click. Misinformation on social media can thus quickly reach many individuals, which can cause confusion and unnecessary anxiety among the public. ${ }^{12}$ However, individual interest also propels the formation and spreading of health misinformation. For instance, we have indicated that some entities are prone to cooking up online misinformation on purpose for earning attentions or clicks. ${ }^{17}$

The health misinformation has a life circle. Research on SARS-related misinformation shows that misinformation responded rather quickly to the SARS outbreak, and its pattern parallels nicely the trajectory of the epidemic overall. ${ }^{7}$ Such situation means that misinformation cannot exist all the time. When a certain information environment is accessible, and the public's anxiety is alleviated, the 
hotbed of health misinformation will be eliminated naturally. $^{12}$

Although we constantly emphasize the importance of combating the misinformation during COVID-19 outbreak, it is necessary to conduct a systematic and indepth analysis of the COVID-19 misinformation prior to recommend effective strategies for health communication and misinformation refuting. Referring to previous research, this article mainly focuses on the specific types of misinformation and their timeline of dissemination. In addition, strategies of health communication are given based on these characteristics.

\section{Method}

The open-access statistics of misinformation database, named "Tencent Facts," is available online, conducted by an Internet media organization named "Tencent" and the Chinese official public health organization "Health Communication Working Committee of Chinese Medical Doctor Association". 35 This database mainly collected misinformation related to COVID-19 from Chinese social media, such as WeChat and Weibo. In order to testify these pieces of misinformation are really wrong, this database also collect the fact-checking materials of all misinformation, aiming to offer authentic information. We extracted 547 pieces of misinformation published from January 18, 2020, when the first misinformation was reported, to
April 30, 2020. The descriptive analysis of this paper is mainly based on this data.

This data classifies the misinformation into six types: (1) Rumor, (2) no ultimate conclusion, (3) inaccuracy, (4) fake scientific knowledge, (5) dependent on the situation, and (6) fake news. The respective meanings of the six types are shown in Table 1.

With respect to the descriptive analysis, this article focuses on three aspects: (1) pieces of misinformation which the public pay the most attention to; (2) in view of the importance of cultural factor, we will investigate whether the cultural and social factor impact people's perception on the misinformation; (3) the development timeline of the misinformation.

We reclassified the 547 pieces of misinformation collected in our study according to their content and thematic prominence. The resultant ten categories are listed in Table 2.

We also collected media reports associated with COVID-19 rumors, including the public's reactions to and comments about the COVID-19 outbreak and its misinformation, as well as expert interviews in official media. From these reports and interviews, we determined how this misinformation was spread and refuted. In addition, we referred to the daily confirmed cases of China, which were retrieved from the official website of the National Health Commission of China. ${ }^{36}$

Table I Classification of the Misinformation Related to COVID-19 in China

\begin{tabular}{|c|c|c|}
\hline Type & Description & Example \\
\hline Rumor & $\begin{array}{l}\text { In this data, the term of rumor is used to represent completely fake news } \\
\text { or messages that have been verified by government or expert. }\end{array}$ & $\begin{array}{l}\text { The unknown pneumonia in Wuhan is } \\
\text { the SARS virus. }\end{array}$ \\
\hline $\begin{array}{l}\text { No ultimate conclusion } \\
\text { (controversial conclusion) }\end{array}$ & $\begin{array}{l}\text { This type is almost equal to Swire-Thompson and Lazer's definition that } \\
\text { the message has not proven by the scientific community, and blindly } \\
\text { following such messages may be ineffective or harmful. }\end{array}$ & $\begin{array}{l}\text { Lopinavir/ritonavir can effectively } \\
\text { remedy COVID-I9. }\end{array}$ \\
\hline Inaccuracy & $\begin{array}{l}\text { The original or a part of the content of the message is genuine or factual; } \\
\text { however, the final version of the message is processed or distorted. }\end{array}$ & $\begin{array}{l}\text { If a disinfectant's name involves chlorine, } \\
\text { it is a chlorine-containing disinfectant. }\end{array}$ \\
\hline $\begin{array}{l}\text { Fake scientific knowledge } \\
\text { (fake common } \\
\text { knowledge) }\end{array}$ & The message has been proven wrong by the scientific community. & Fireworks can prevent the epidemic. \\
\hline $\begin{array}{l}\text { Dependent on the } \\
\text { situation }\end{array}$ & Such a message is factual only in specific situations. & $\begin{array}{l}\text { N95 masks should be changed every } \\
\text { four hours. }\end{array}$ \\
\hline Fake news & $\begin{array}{l}\text { Created news for attracting clicks and followers, or for entertainment } \\
\text { purposes. }\end{array}$ & $\begin{array}{l}\text { Brazilian President Jair Bolsonaro was } \\
\text { confirmed as having COVID-19. }\end{array}$ \\
\hline
\end{tabular}

Note: Summarized from Real-Time Rumors Refuting of the Novel Coronavirus Pneumonia. ${ }^{35}$ 
Table 2 Different COVID-19 Misinformation Contents

\begin{tabular}{|c|c|c|c|c|}
\hline Category & Explanation & Example & $\mathbf{N}$ & $\%$ \\
\hline $\begin{array}{l}\text { Preventive and } \\
\text { therapeutic } \\
\text { methods }\end{array}$ & $\begin{array}{l}\text { Curative medicine and preventive methods of } \\
\qquad \text { COVID- } 19 .\end{array}$ & $\begin{array}{l}\text { January 21, 2020: Vitamin C can prevent COVID-19. } \\
\text { January 23, 2020: Oseltamivir can cure COVID-19. }\end{array}$ & 234 & 42.78 \\
\hline $\begin{array}{l}\text { Epidemiological } \\
\text { characteristics of } \\
\text { COVID-19 }\end{array}$ & Related epidemiological characteristics. & $\begin{array}{l}\text { January 26, 2020: COVID-19 is an evolution of the SARS virus. } \\
\text { April 23, 2020: The } R_{0} \text { of COVID-19 is 5.07, which is higher than } \\
\text { that of common pandemics. }\end{array}$ & 53 & 9.69 \\
\hline $\begin{array}{l}\text { Restoration of } \\
\text { normal production } \\
\text { and life }\end{array}$ & $\begin{array}{l}\text { The date and schedule of restoring schooling, } \\
\text { production, and living. }\end{array}$ & $\begin{array}{l}\text { February 23, 2020: The Shanghai government has officially } \\
\text { announced that school is beginning May I, } 2020 \text {. }\end{array}$ & 32 & 5.85 \\
\hline $\begin{array}{l}\text { International and } \\
\text { domestic travel } \\
\text { restrictions }\end{array}$ & $\begin{array}{l}\text { Policies of travel restriction issued by China's } \\
\text { government and other countries' } \\
\text { governments. }\end{array}$ & $\begin{array}{l}\text { January } 25,2020 \text { : Singapore rejects } 116 \text { tourists coming from } \\
\text { Wuhan. } \\
\text { January 26, 2020: Guangzhou government will take the lockdown } \\
\text { of the whole city. }\end{array}$ & 26 & 4.75 \\
\hline $\begin{array}{l}\text { Domestic (China) } \\
\text { outbreak situation }\end{array}$ & $\begin{array}{l}\text { Severe situations and reappearances of } \\
\text { COVID-19 in China. }\end{array}$ & $\begin{array}{l}\text { April 18, 2020: Numerous people in white protective clothing } \\
\text { appeared at the Beijing West Railway Station, which meant a new } \\
\text { COVID-19 outbreak had started. }\end{array}$ & 38 & 6.95 \\
\hline $\begin{array}{l}\text { International } \\
\text { outbreak situation }\end{array}$ & $\begin{array}{l}\text { Severe situations of COVID-19 outbreak } \\
\text { outside of China. }\end{array}$ & $\begin{array}{l}\text { February 22, 2020: A proportion of the } 14,000 \text { influenza-related } \\
\text { deaths in America were actually caused by COVID-19. } \\
\text { February 24, 2020: An American whistleblower has disclosed that } \\
\text { the number of infected people has exceeded } 1000 \text {. }\end{array}$ & 24 & 4.39 \\
\hline $\begin{array}{l}\text { Policies responding } \\
\text { to COVID-19 }\end{array}$ & $\begin{array}{l}\text { Official policies responding to COVID-19 } \\
\text { issued by China's multi-level governments. }\end{array}$ & $\begin{array}{l}\text { February 3, 2020: China's state council have banned all sales } \\
\text { platforms from selling masks. } \\
\text { February 4, 2020: Wuhan will conduct military control if the } \\
\text { outbreak does not improve. }\end{array}$ & 50 & 8.96 \\
\hline $\begin{array}{l}\text { Confirmed cases of } \\
\text { special people }\end{array}$ & $\begin{array}{l}\text { Special people, such as celebrities, politicians, } \\
\text { and medical workers, were confirmed as being } \\
\text { infected. }\end{array}$ & $\begin{array}{l}\text { February 28, 2020: Movie Star Jackie Chan has been infected. } \\
\text { April 3, 2020: Singapore premier Lee Hsien Loong has been } \\
\text { infected. }\end{array}$ & 21 & 3.84 \\
\hline $\begin{array}{l}\text { Conspiracy } \\
\text { theories }\end{array}$ & $\begin{array}{l}\text { Conspiracy theory associated with the virus } \\
\text { source or biological warfare. }\end{array}$ & $\begin{array}{l}\text { February 3, 2020: The coronavirus is synthetic. } \\
\text { February 28, 2020: The coronavirus originated from the United } \\
\text { States. }\end{array}$ & 11 & 2.01 \\
\hline Others & Fake news related to social life. & $\begin{array}{l}\text { February 14, 2020: An infant born in Zhejiang province was named } \\
\text { Dai Kou Zhao (Chinese expression of Wearing Mask). }\end{array}$ & 59 & 10.79 \\
\hline Overall & & & 547 & 100 \\
\hline
\end{tabular}

Note: Summarized from Real-Time Rumors Refuting of the Novel Coronavirus Pneumonia. ${ }^{35}$

\section{Results}

\section{Thematic Focus of COVID-I9 Misinformation for the Public}

Table 2 shows that misinformation related to preventive and therapeutic methods constitutes over $40 \%$ of the collected pieces $(42.78 \%)$, which is the mostmentioned type of misinformation. Although there is an array of other categories in the sequence, there is no prominent difference between these categories. For instance, the second type refers to epidemiological characteristics of COVID-19, but the variance is not significant compared to the other eight categories. Surprisingly, misinformation associated with conspiracy theories, which has been discussed by official media, politicians, and celebrities, occupies the least amount of COVID-19 misinformation. ${ }^{37,38}$

In order to illustrate the most-mentioned misinformation from multiple perspectives, we also applied a word frequency analysis of all misinformation using the online software PicData, and thus determined the ten most used words or phrases, as shown in Table 3. 
Table 3 Top-Ten Most Frequent Words of the COVID-19 Misinformation

\begin{tabular}{|l|c|c|c|}
\hline & Keyword & Frequency (Count) & Weight \\
\hline 1 & Prevention & 58 & 0.8437 \\
2 & Infection & 53 & 0.8391 \\
3 & Mask & 48 & 0.8752 \\
4 & Wuhan & 42 & 0.8143 \\
5 & Therapy & 27 & 0.7631 \\
6 & Disinfection & 25 & 0.7724 \\
7 & American & 25 & 0.7399 \\
8 & Patient & 20 & 0.7389 \\
9 & School start & 18 & 0.7286 \\
10 & Zhong Nanshan & 18 & 0.7312 \\
\hline
\end{tabular}

Notes: $p<0.01$. Following instructions of the online software, the algorithm of "weight" is jointly determined by word frequency, resolving the power of words, and the level of semantic aggregation. Data came from Real-Time Rumors Refuting of the Novel Coronavirus Pneumonia. ${ }^{35}$ The online software is accessible via http:// www.picdata.cn/.

We reviewed the pieces of misinformation in which these high-frequency words appeared, and then summarized our findings as follows: (1) The words "prevention," "infection," "mask," "therapy," "disinfection," and "patient" are interconnected, confirming that misinformation associated with preventive and therapeutic methods was the most common. For example, "Antibiotics can prevent and remedy COVID19," "Electric masks can prevent the coronavirus," "Chinese balm can prevent people from infection," "A common disinfectant can eliminate the coronavirus," and "Germany has cured four COVID-19 patients by atomizing therapy." (2) Since Wuhan is the city in which the first case was identified, it is natural that people are constantly concerned with Wuhan's situation. The local headlines included "All supermarkets and pharmacies will shut down after three days" and "Wuhan will enforce military control if the outbreak fails to [improve] after February 10." (3) Twenty pieces of misinformation were connected to America; however, only four were related to conspiracy theories and the furious debate of the source of the coronavirus between China and America. Thus, the public focus may not have been on conspiracy theories. (4) All misinformation with the phrase "school start" pointed toward the date of the reopening of school. After the resumption of work across China, the date of educational agencies, including elementary schools, high schools, and universities, remains uncertain, which perhaps is the cause of the spread of misinformation about when school starts. (5) Zhong Nanshan is a famous expert of respirology who enjoys high prestige. Creating and spreading misinformation in the name of a celebrity such as Zhong
Nanshan enables social media to attract more clicks and followers.

\section{Traditional Chinese Medicine Plus "Folk Prescription" versus "Western Medicine"} Chinese people have a stubborn belief about TCM. In addition, folk prescription (FP) or folk medicine, which involves folk experiences of food therapy or simple naturopathy, is also embedded in Chinese people's cognitive processes, and generally, people believe that FP has a unique effect on some illnesses. Briefly, compared to Western medicine (WM), TCM and FP are based on Chinese philosophy, the potential effects, and folk beliefs; they are not based on evidence and scientific experiments.

We extracted 69 pieces of misinformation associated with TCM, FP, and WM for comparative study. These pieces of misinformation were diffused among different types of misinformation, namely, rumors, no ultimate conclusion (controversial conclusion), and fake scientific knowledge (fake common knowledge), and Table 4 illustrates these pieces of misinformation and the types to which they are attributed.

Table 4 shows that the number of pieces of TCM and FP misinformation is more than twice that of WM. This result reflects that cultural and social factors have a strong impact on people's beliefs about health consciousness, and such consciousness even makes people ignore evidencebased and scientific health behavior. Among the TCM- and FP-related misinformation, the majority of these pieces take the form of "X can prevent COVID-19," and this form matches Chinese people's traditional cognition of TCMs as "causal treatments" and "treatments before

Table 4 Comparison Between Traditional Chinese Medicine (TCM)- and Folk Prescription (FP)-Related Misinformation and Western Medicine (WM)-Related Misinformation

\begin{tabular}{|l|c|c|c|c|}
\hline & Rumors & $\begin{array}{c}\text { No Ultimate } \\
\text { Conclusion } \\
\text { (Controversial } \\
\text { Conclusion) }\end{array}$ & $\begin{array}{c}\text { Fake } \\
\text { Scientific } \\
\text { Knowledge } \\
\text { (Fake } \\
\text { Common } \\
\text { Knowledge) }\end{array}$ & Total \\
\hline TCM & 4 & 12 & 2 & $18(26.09 \%)$ \\
FP & 20 & 0 & 10 & $30(43.48 \%)$ \\
WM & 11 & 8 & 2 & $21(30.43 \%)$ \\
Total & 35 & 20 & 14 & $69(100 \%)$ \\
\hline
\end{tabular}

Note: Summarized from Real-Time Rumors Refuting of the Novel Coronavirus Pneumonia. ${ }^{35}$ 
getting [the] illness," thus speeding up the process of spreading misinformation. With respect to the various categories of these misinformation pieces, 12 had no ultimate conclusion (controversial conclusion), which means that evidence-based research regarding the TCM is ongoing. However, all pieces of FP-related misinformation are rumors or fake scientific knowledge (fake common knowledge). This means that all of this misinformation has no scientific evidence and may be disgusting. For instance, a FP-related misinformation indicates that a "virgin's urine can prevent COVID-19." In addition, some TCM misinformation, such as that related to Areca catechu (Binglang), Realgar (Xionghuang), and Paris polyphylla (Chonglou), has been proven to be toxic if attempted. Therefore, the health information that people transmit or spread, to a great extent, depends on people's individual cognition rather than scientific evidence.

\section{Timelines of Misinformation versus an Increase in Confirmed Cases}

The misinformation spreading style differs in disaster situations compared to in normal situations. Especially in the age of modern technologies and instantaneous communication, a health emergency also gives rise to another important and terrifying crisis: infodemic. ${ }^{39}$ However, little is known about whether the spread of misinformation is correlated with the actual situation of the crisis.

Figure 1 visually interprets the timelines of misinformation and confirmed cases by using weekly data. In order to avoid variances of several extremums, we used weekly data instead of daily data. For instance, the number of new cases on February 12 was 15,152 due to a change in the statistical method. ${ }^{36}$

According to Figure 1, the overall trends of the two timelines are notably correlated. During the initial stage, the number of confirmed cases and misinformation are sharply increased. After the peak, both lines show a downward trend. However, as the figure shows, the peak number of misinformation pieces predates the number of confirmed cases. During its decline, the number of misinformation pieces fluctuated more notably than that of the confirmed cases. As the number of confirmed cases approaches zero, new misinformation, however, continues to appear on social media.

We can conclude from Figure 1 that the temporal characteristics of the production and spread of health misinformation is in accord with the tread of crises. The emergence and spread of misinformation during health crises typically begins at the interpersonal level through various channels - in this case, due to the uncertain, threatening, and ambiguous context of COVID-19. The large number of uncertain facts regarding COVID-19 during the initial stage accelerated the propagation of misinformation, particularly based on the broadcasting feature of misinformation. As the outbreak approached the turning point, much disease-related information was evidenced by the academic community as well. The proliferation of certain facts restricted the space of misinformation, which led to a turning point in the amount of the misinformation.

Figure 2 shows a trend comparison of the misinformation of "Preventive and Therapeutic Methods" and that of the "Restoration of Normal Production and Life." It maps out that, at the earlier stage of the outbreak, misinformation regarding "Preventive and Therapeutic Methods" was the main type. Thus, the higher the perceived severity, the more likely one is to avoid a threatening situation. Such emotions were a conduit for conveying the misinformation of "Preventive and Therapeutic Methods". As the outbreak was controlled effectively, the resumption of work was a priority for the public. However, in many cities in China, the government did not issue an official document informing the public of the specific time for the resumption of work and school. Therefore, misinformation regarding the "Restoration of Normal Production and Life" emerged. Especially for school, the government tended to delay making any decisions, because the reopening of school would trigger large-scale clustering, thus affording an opportunity for the spread of related misinformation. For example, 17 out of 32 pieces of misinformation on the "Restoration of Normal Production and Life" were about the resumption of schooling.

With the completion of the overall resumption of work across the country in late April, this type of misinformation basically disappeared.

\section{Strategies for Combating the Misinformation During COVID-I 9 Outbreak}

The production and spread of health misinformation on social media have become a vital problem, especially during public health emergencies. As mentioned, the COVID-19 outbreak is not only a pandemic, but also an infodemic, and effective solutions will almost certainly require a combination of a wide range of approaches. ${ }^{40}$ Based on the abovementioned 


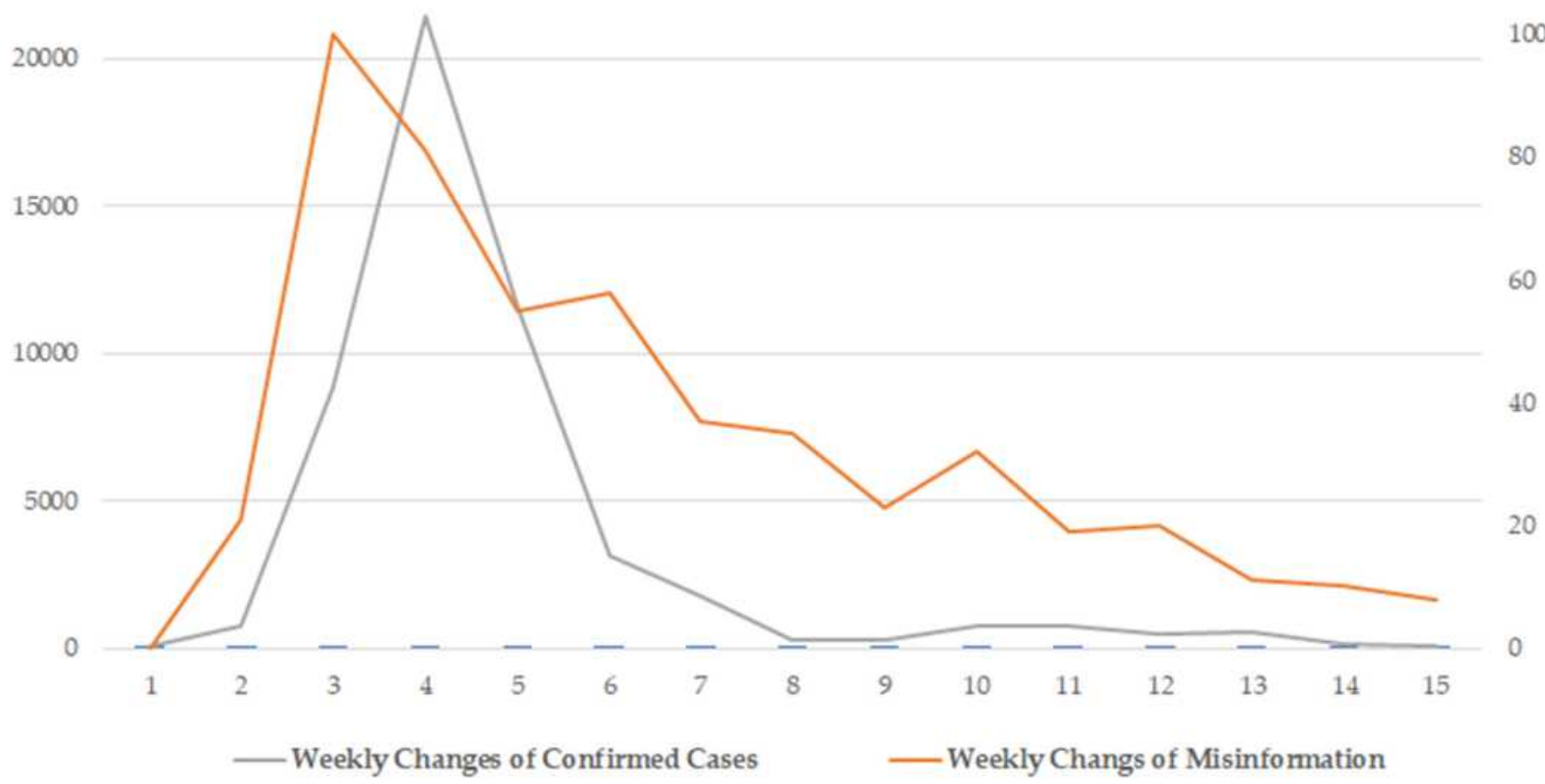

Figure I Timelines of misinformation and confirmed cases by using weekly data.

Note: Weekly data of misinformation calculated from Real-Time Rumors Refuting of the Novel Coronavirus Pneumonia.

results, some recommendations are given to correct misinformation and offer genuine health information on social media.

Provide Timely and Accurate Information About Health and Life in an

\section{Understandable Way}

The results of this article indicate that people mainly focus on the information related to their daily lives, including health risks, health guidelines, and the normal life order.
Therefore, approaches combating misinformation ought to target this domain and provide timely and accurate information about health and life. For the professional issue of public health, a strategy for communication is to explain these concerning issues in a way that is easy to understand, where plain language is utilized to convey the scientific rationale behind the prevention guidelines. ${ }^{41}$ In addition, it is necessary to emphasize every element in a piece of health information in order to avoid misleading and

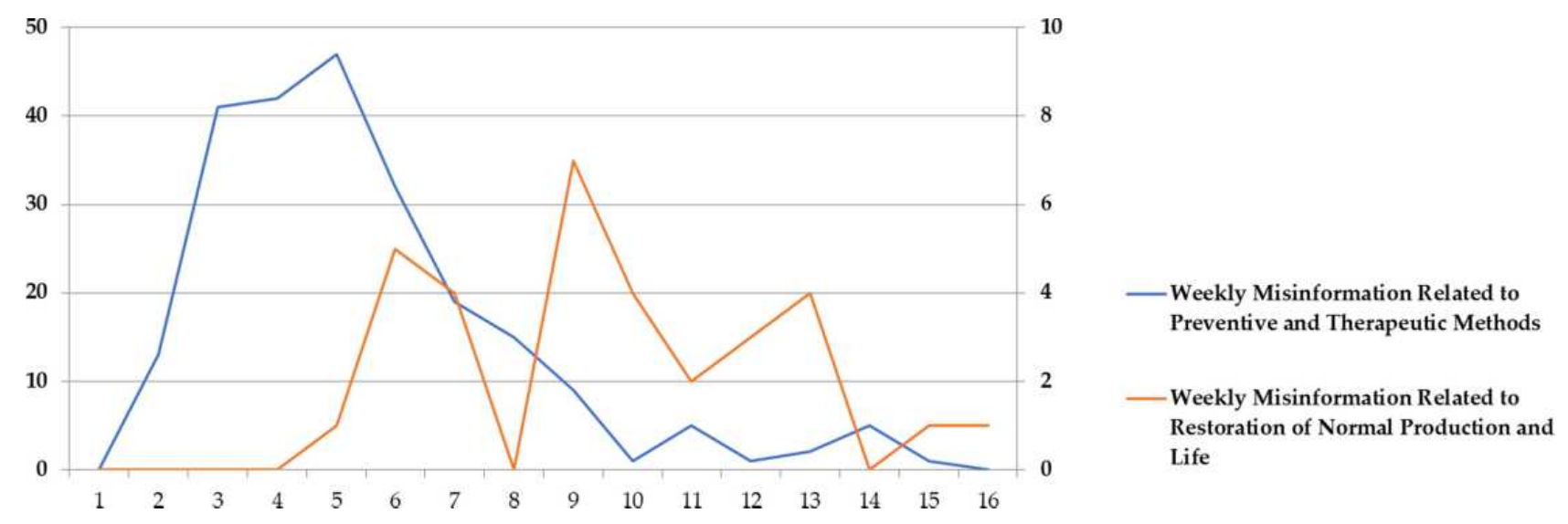

Figure 2 Comparison of the trends of the misinformation of "Preventive and Therapeutic Methods" and "Restoration of Normal Production and Life." Note: Weekly data of misinformation calculated from Real-Time Rumors Refuting of the Novel Coronavirus Pneumonia. 
vague expressions, and to prevent any ambiguous content from becoming misinformation. Although In the context of the universal audience, vague and abstract messages are a prerequisite, due to the cultural variables shaping a particular audiences' perspectives, providing specific instructions predicated on the elite's perspective of what all rational people would accept as fact is not effective. A shift to the approach enabling each particular audience to participate in the process of establishing interacting arguments is more productive for the risk communicator. $^{42}$ Though refuting misinformation is necessary, post-action is not as effective as pre-action, such as publishing accurate, certain, and high-quality information.

\section{Offer Targeted and Accurate Information in Advance Based on Predictions of the Prospective Outbreak Situation}

Our results reveal that the trend of misinformation has a significant correlation with the severity and situation of the emergency. Thus, one of the ways to eliminate hotbeds of misinformation is to offer continuously targeted and accurate information in advance based on predictions of the prospective COVID-19 outbreak situation. In the environment of an information vacuum, the way in which to fill said vacuum depends upon which information source, whether accurate or false, can respond more promptly. The "butterfly effect" of opaque information communication may result in a number of consequences, and this has been evidenced by China's early response to the COVID-19 outbreak. $^{41}$ Integrating the abovementioned aspects, communication, accordingly, is influenced by contextual dynamics. Effective communication is a timely, dynamic, and transparent process, and organizations and media ought to update communication as additional information becomes available. ${ }^{43}$ Therefore, in an open and transparent process, all risk stakeholders have the opportunity to access the genuine information and express their positions. ${ }^{42}$

\section{Credible Information Source is Important}

Our results are also relevant because the principle that misinformation is veiled by experts' statements can attract more attention and reposts. Such a phenomenon shows that it is effective to enhance people's scientific health perception and to curb health misinformation if credible experts are responsible for health communication in a timely way. Currently, many experts, health professionals, and organizations have their own social media accounts on various platforms. Take China, for instance; many public health authorities at different levels have accounts on social media platforms, such as the commonly used WeChat and Weibo. If credible experts were to use these social media platforms, the effective delivery of high-quality information and the correction of misinformation before and during health-related crises could be achieved, as well as a further reduction in the amount of misinformation circulating on social media. ${ }^{44}$

\section{Health Communication Ought to Conform to People's Habitual Beliefs}

Our results also uncover the connection between traditional beliefs or perceptions and health misinformation, which reflects that misinformation management has to consider the cultural cradle in relation to the spread of misinformation. The existing literature indicates that when misinformation correction is ongoing, deeply established beliefs about misinformation are difficult to overcome. ${ }^{45}$ For misinformation related to TCM or FP, people's strong beliefs lead to massive and even absurd misinformation. The policy recommendations suggested by these findings should focus on communication strategies. If traditional beliefs are difficult to "overturn", a better strategy is to "permeate." First, health experts can use a gradual method to change a specific group's health behaviors and to further change that of other groups step-by-step. Changing a specific group's health behavior first will guide the public to understand a scientific health perception, which can be regarded as a premise for changing everyone's health behavior. Second, adopting a factual and scientific alternative that matches people's traditional perceptions is more easily accepted by the public. ${ }^{46}$

\section{Conclusions and Discussion}

This article illustrated the characteristics of the misinformation on social media during the COVID-19 public health emergency in China, and further provided implications on health communication for preventing and rebuking misinformation during a public health emergency. Particularly, this article showed these characteristics based on an entire evolution process of misinformation during this public health emergency. The creation and spread of misinformation related to a public health emergency has its thematic focus, its cultural and social factors, 
and a developmental process. The recommendations of this article offer targeted and effective management strategies for responding to misinformation on social media, which can be used to tackle the current COVID-19 outbreak across the world and can provide lessons for future health risk communication and misinformation research.

On the basis of this study, for combating misinformation on social media, the solution is likely not a single effort to correct misinformation or to prevent its spread. Instead, scholars, journalists, educators, and citizens must collaboratively identify and correct any misinformation. In this network, there is no doubt that social media ought to take more responsibility as an information source. Social media platforms are capable of skipping traditional gatekeepers, such as professional editors or peer reviewers, and have contributed to the increased dissemination of misinformation. Especially during a public health emergency, misinformation propaganda endangers people by installing misleading risk perceptions and health behaviors and reinforcing social fear. ${ }^{47}$ Therefore, it is important for social media to check health information thoroughly and rigorously, and to allow experts or professionals to review and question the information and make dynamic evidencebased corrections. Moreover, authorities ought to improve the monitoring of health and other information related to people's security during a public health emergency, and to strictly penalize social media when they create or disseminate misinformation maliciously. Applying technology is also an effective method to control health misinformation. Pennycook and Rand's work offers us a reference: They argue that having algorithms up-rank content from trusted media outlets may be a promising approach for fighting the spread of misinformation on social media. ${ }^{48}$

This article also has limitations that should be further addressed in future research. First, it was based on a single case, and the effects of communication strategies for extensive practice ought to be flexible according to different contexts. As the utilization of vaccine, vaccine misinformation could be a useful follow-up study. In addition, without further logistic analysis, we cannot clearly argue what the correlation is between misinformation spread and the public's characteristics, which would enable us to understand why people are prone to believing and disseminating misinformation during a public health emergency. Future research should expand analysis to understand if there is an association or correlation between misinformation and people's perceptions and behaviours. As Cook et al put forward, there is much potential in an interdisciplinary approach, involving, for example, psychology, computer science, political science, and pedagogy, which presents exciting opportunities in terms of responding to misinformation in innovative and systematic ways. ${ }^{47}$

\section{Disclosure}

The authors declare no conflicts of interest in this work.

\section{References}

1. Han S, Zhuang F, He Q, et al. Energy model for rumor propagation on social networks. Physica A. 2014;394:99-109. doi:10.1016/j. physa.2013.10.003

2. Shin J, Jian L, Driscoll K, et al. Political rumoring on twitter during the 2012 us presidential election: rumor diffusion and correction. New Media Soc. 2016;19(8):1214-1235. doi:10.1177/1461444816634054

3. Sohu. How many pieces of misinformation do you believe from the 10 misinformation on WeChat moment? Available from: https:// www.sohu.com/a/288294271_570570. Accessed August 20, 2020.

4. DiFonzo N, Bordia P. Rumor Psychology: Social and Organizational Approaches. American Psychological Association; 2007.

5. Zarocostas J. How to fight an infodemic. Lancet. 2020;395 (10225):676. doi:10.1016/S0140-6736(20)30461-X

6. Kaler A. Health interventions and the persistence of rumour: the circulation of sterility stories in African public health campaigns. Soc Sci Med. 2009;68(9):1711-1719. doi:10.1016/j.socscimed.2009.01.038

7. Tai Z, Sun T. The rumouring of SARS during the 2003 epidemic in China. Sociol Health Illne. 2011;33(5):677-693. doi:10.1111/j.14679566.2011.01329.x

8. World Health Organization. Statement on the second meeting of the international health regulations (2005) emergency committee regarding the outbreak of novel coronavirus (2019-nCoV). Available from: https://www.who.int/news-room/detail/30-01-2020-statement-on-thesecond-meeting-of-the-international-health-regulations-(2005)emergency-committee-regarding-the-outbreak-of-novel-coronavirus -(2019-ncov.). Accessed August 20, 2020.

9. World Health Organization. WHO director-general's opening remarks at the media briefing on COVID-19. Available from: https://www. who.int/dg/speeches/detail/who-director-general-s-opening-remarksat-the-media-briefing-on-covid-19-20-march-2020. Accessed August 20, 2020.

10. Hao K, Basu T. The Coronavirus is the first true social-media "infodemic". Available from: https://www.technologyreview.com/2020/02/ 12/844851/the-coronavirus-is-the-first-true-social-media-infodemic/. Accessed August 20, 2020.

11. World Health Organization. Munich security conference. Available from: https://www.who.int/dg/speeches/detail/munich-securityconference. Accessed August 23, 2020.

12. Van der Meer TA, Jin Y. Seeking formula for misinformation treatment in public health crises: the effects of corrective information type and source. Health Commun. 2020;35(5):560-575. doi:10.1080/ 10410236.2019.1573295

13. World Health Organization. COVID-19 preparedness \& response. Available from: https://www.who.int/emergencies/diseases/novelcoronavirus-2019/technical-guidance/risk-communication-andcommunity-engagement. Accessed August 23, 2020.

14. World Health Organization. Strategic advisory group of experts onImmunization. Available from: https://www.who.int/immuniza tion/sage/SAGE_YB_Nov_2011.pdf. Accessed August 23, 2020.

15. China Daily. Curbing "infodemic" crucial to epidemic battle: China Daily editorial. Available from: http://www.chinadaily.com.cn/a/ 202003/02/WS5e5d0fc2a31012821727bb1b.html. Accessed August $30,2020$. 
16. Chou WS, Oh A, Klein WMP. Addressing health-related misinformation on social media. JAMA. 2018;320(23):2417-2418. doi:10.1001/ jama.2018.16865

17. Swire-Thompson B, Lazer D. Public health and online misinformation: challenges and recommendations. Annu Rev Public Health. 2020;41(1):433-451. doi:10.1146/annurev-publhealth-040119094127

18. Al Khaja KJ, AlKhaja AK, Sequeira RP. Drug information, misinformation, and disinformation on social media: a Content Analysis Study. J Public Health Pol. 2018;39(3):343-357. doi:10.1057/ s41271-018-0131-2

19. Miroslav T, Mikelic N. Information science: science about information misinformation and disinformation. Available from: http://pro ceedings.informingscience.org/IS2003Proceedings/index.html. Accessed August 30, 2020.

20. Edelman MJ. The Politics of Misinformation. Cambridge University Press; 2001.

21. Tandoc E, Lim Z, Ling R. Defining "fake news. Digit J. 2018;6:137-153. doi:10.1080/21670811.2017.1360143

22. Bergmann E. Conspiracy \& Populism: The Politics of Misinformation. Palgrave Macmillan; 2018.

23. Zhang L, Chen K, Jiang H, et al. How the health rumor misleads people's perception in a public health emergency: lessons from a purchase craze during the COVID-19 outbreak in China. Int J Environ Res Public Health. 2020;17(19):7213. doi:10.3390/ ijerph 17197213

24. Wikipedia. Misinformation related to the COVID-19 pandemic. Available from: https://en.wikipedia.org/wiki/Misinformation related to the $2019 \% \mathrm{E} 2 \% 80 \% 9320$ coronavirus pandemic\#China 3. Accessed August 30, 2020.

25. Floridi L. The Philosophy of Information. Oxford University Press; 2011.

26. Skyrms B. Signals: Evolution, Learning, and Information. Oxford University Press; 2010.

27. O'Connor C, Weatherall J. The Misinformation Age: How False Beliefs Spread. Yale University Press; 2019.

28. Zollo F, Quattrociocchi W. Complex Spreading Phenomena in Social Systems. Springer; 2018.

29. Rosnow RL. Rumor as communication: a contextualist approach. J commun. 1988;38(1):12-28. doi:10.1111/j.1460-2466.1988.tb02033.x

30. Fung IC, Fu K, Chan $\mathrm{C}$, et al. Social media's initial reaction to information and misinformation on ebola, August 2014: facts and rumors. Public Health Rep. 2016;131(3):461. doi:10.1177/ 003335491613100312

31. Rosnow RL, Esposito JL, Gibney L. Factors influencing rumor spreading: replication and extension. Lang Commun. 1988;8 (1):29-42. doi:10.1016/0271-5309(88)90004-3

32. Pezzo MV, Beckstead JW. A multi-level analysis of rumor transmission: effects of anxiety and belief in two field experiments. Basic Appl Soc Psych. 2006;28(1):91-100. doi:10.1207/ s15324834basp2801_8

33. Freedman DA, Bess KD, Tucker HA, et al. Public health literacy defined. Am J Prev Med. 2009;36(5):446-451. doi:10.1016/j. amepre.2009.02.001

Risk Management and Healthcare Policy

\section{Publish your work in this journal}

Risk Management and Healthcare Policy is an international, peerreviewed, open access journal focusing on all aspects of public health, policy, and preventative measures to promote good health and improve morbidity and mortality in the population. The journal welcomes submitted papers covering original research, basic science, clinical \& epidemiological studies, reviews and evaluations,
34. Chen X, Sin SJ, Theng YL, et al. Why students share misinformation on social media: motivation, gender, and study-level differences. J Acad Libr. 2015;41(5):583-592. doi:10.1016/j.acalib.2015.07.003

35. Tencent Fact. Real-time rumors refuting of the novel coronavirus pneumonia. Available from: https://vp.fact.qq.com/home?ADTAG= wx.kyk\%20. Accessed August 20, 2020.

36. National Health Commission of China. Situation update of the novel coronavirus pneumonia up to $12 \mathrm{pm}$, February 23. Available from: http:// www.nhc.gov.cn/xcs/yqtb/202002/26fb16805f024382bff1de80c918368f. shtml. Accessed August 20, 2020.

37. Lynas M. COVID: top 10 current conspiracy theories. Cornell alliance for science; 2020. Available from: https://allianceforscience. cornell.edu/blog/2020/04/covid-top-10-current-conspiracy-theories/. Accessed April 29, 2020.

38. Muller RT. COVID-19 brings a pandemic of conspiracy theories: conspiracy theories bloom in periods of uncertainty and threat. Available from: https:/www.psychologytoday.com/us/blog/talkingabout-trauma/202004/covid-19-brings-pandemic-conspiracy-theories. Accessed August 30, 2020.

39. Miyabe M, Nadamoto A, Aramaki E. How do rumors spread during a crisis? Analysis of rumor expansion and disaffirmation on twitter after 3.11 in Japan. Int $J$ Web Inf Sys. 2014;10(4):394-412. doi:10.1108/ijwis-04-2014-0015

40. Tian RY, Zhang XF, Liu YJ. SSIC model: a multi-layer model for intervention of online rumors spreading. Physica $A$. 2015;427:181-191. doi:10.1016/j.physa.2015.02.008

41. Zhang L, Li H, Chen K. Effective risk communication for public health emergency: reflection on the COVID-19 (2019-nCoV) outbreak in Wuhan, China. Healthcare. 2020;8(1):64. doi:10.3390/ healthcare 8010064

42. Sellnow TL, Ulmer RR, Seeger MW, Littlefield R. Effective Risk Communication: A Message-Centered Approach. New York: Springer; 2009.

43. Hyer RN, Covello VT. Effective media communication during public health emergencies: a WHO handbook; 2007. Available from: https:// www.semanticscholar.org/paper/Effective-Media-CommunicationDuring-Public-Health-Hyer-Covello/cf04d41d39d04a0586c4b1 f0a54202a9b7eedf5f. Accessed August 30, 2020.

44. Eckert S, Sopory P, Day A, et al. Health-related disaster communication and social media: mixed-method systematic review. Health Commun. 2018;33(12):1389-1400. doi:10.1080/10410236.2017.1351278

45. Leticia B, Vraga EK. In related news, that was wrong: the correction of misinformation through related stories functionality in social media. J Commun. 2015;65(4):619-638. doi:10.1111/jcom.12166

46. Johnson HM, Seifert CM. Sources of the continued influence effect: when misinformation affects later inferences. $J$ Exp Psychol. 1994;20:1420-1436. doi:10.1037/0278-7393.20.6.1420

47. Cook J, Ecker U, Lewandowsky S. Misinformation and how to correct it. In: Scott R, Kosslyn S, editors. Emerging Trends in the Social and Behavioral Sciences. John Wiley \& Sons; 2015.

48. Pennycook G, Rand DG. Fighting misinformation on social media using crowdsourced judgments of news source quality. PNAS. 2019;116(7):2521-2526. doi:10.1073/pnas.1806781116/-/DCSupple mental

guidelines, expert opinion and commentary, case reports and extended reports. The manuscript management system is completely online and includes a very quick and fair peer-review system, which is all easy to use. Visit http://www.dovepress.com/testimonials.php to read real quotes from published authors. 